\section{Genetic counselors: translating genomic science into clinical practice}

\author{
Robin L. Bennett, ${ }^{1}$ Heather L. Hampel, ${ }^{2}$ Jessica B. Mandell, ${ }^{3}$ \\ and Joan H. Marks ${ }^{4}$
}

\author{
${ }^{1}$ Medical Genetics Clinic, University of Washington, Seattle, Washington, USA \\ ${ }^{2}$ The Ohio State University, College of Medicine and Public Health, Columbus, \\ Ohio, USA \\ ${ }^{3}$ King Laboratory, Departments of Medicine and Genome Sciences, \\ University of Washington, Seattle, Washington, USA \\ ${ }^{4}$ Human Genetics Program, Sarah Lawrence College, Bronxville, New York, USA
}

In a time of emerging genetic tests and technologies, genetic counselors are faced with the challenge of translating complex genomic data into information that will aid their client's ability to learn about, understand, make, and cope with decisions relating to genetic diagnoses. The first of two companion articles in this issue (see the related article beginning on page 1280) examines the role of the genetic counselor, particularly in counseling individuals at risk for or diagnosed with breast cancer, in an era of high-tech health care and gene patents.

J. Clin. Invest. 112:1274-1279 (2003). doi:10.1172/JCI200320113.

While 2003 marks the 50th anniversary of Watson and Crick's landmark discovery of the DNA helix, it also marks the 34th anniversary of the beginning of a new breed of masters-trained health professionals - genetic counselors. The field of genetic counseling developed from a need to educate, manage, and counsel individuals and families diagnosed with, or at risk for, genetic diseases with respect to how these conditions affect the psychological, medical, financial, and social aspects of one's life. Genetic counselors are at the forefront of introducing and applying the advances from genome

Address correspondence to: Robin L. Bennett, University of Washington, Medical Genetics, Box 357720, Seattle, Washington 98195-7720, USA. Phone: (206) 616-2135; Fax: (206) 616-2414;

E-mail: robinb@u.washington.edu.

Conflict of interest: The authors have declared that no conflict of interest exists. Nonstandard abbreviations used: National Society of Genetic Counselors (NSGC); American Board of Genetic Counseling (ABGC); hereditary breast-ovarian cancer syndrome (HBOC). science to the lives of individuals and their families.

Genetic counselors' work involves all stages of the life cycle, from preconception counseling to prenatal diagnosis, the diagnosis of newborns or pediatric genetic disorders, and the diagnosis of elderly individuals with inherited predisposition to diseases such as cancer, presenile dementia, psychiatric disorders, and heart disease. Genetic counseling sessions with clients and their families may involve a one-time crisis intervention dealing with a new genetic diagnosis or may develop into a relationship over many years if the client is treated in a specialty clinic for diseases like muscular dystrophy, fragile X syndrome, cystic fibrosis, or Huntington disease.

Genetic counselors are expert educators, skilled in translating the complex language of genomic medicine into terms that are easy to understand. According to the 2002 Professional Status Survey of the National Society of Genetic Counselors (NSGC) (www.nsgc.org), over $75 \%$ of genetic counselors are involved in educating physicians, medical students, nurses and other health professionals, community organizations, undergraduates, and grammar and high school students. While the majority of genetic counselors work in university medical centers, hospitals (private and public), or large medical facilities, an increasing number work with diagnostic laboratories and pharmaceutical companies and in positions related to the development of government and public policy. Genetic counselors are also uniquely trained to work as research coordinators for genetic research studies.

The term "genetic counselor" describes a masters-level health professional with extensive training in human genetics and counseling skills. The first group of ten genetic associates graduated from Sarah Lawrence College in 1971 (1). Today there are 28 programs accredited by the American Board of Genetic Counseling (ABGC) in the US and Canada, and similar programs are in place in the United Kingdom, South Africa, and Australia. The ABGC has certified genetic counselors since 1993. Graduates from genetic counseling programs accredited by the ABGC demonstrate competency in 27 areas within four critical domains: communication; critical thinking; interpersonal counseling and psychosocial assessment; and professional ethics and values (2). Coursework in genetic counseling training programs involves human genetics, cytogenetics, developmental biology and embryology, teratology, statistics, qualitative and quantitative research, counseling and communication skills, interviewing, ethics, and public health. Skills are obtained by a combination of role playing and comprehensive fieldwork in a variety of practice settings.

\section{The practice and process} of genetic counseling

The definition of genetic counseling adopted by the American Society of 


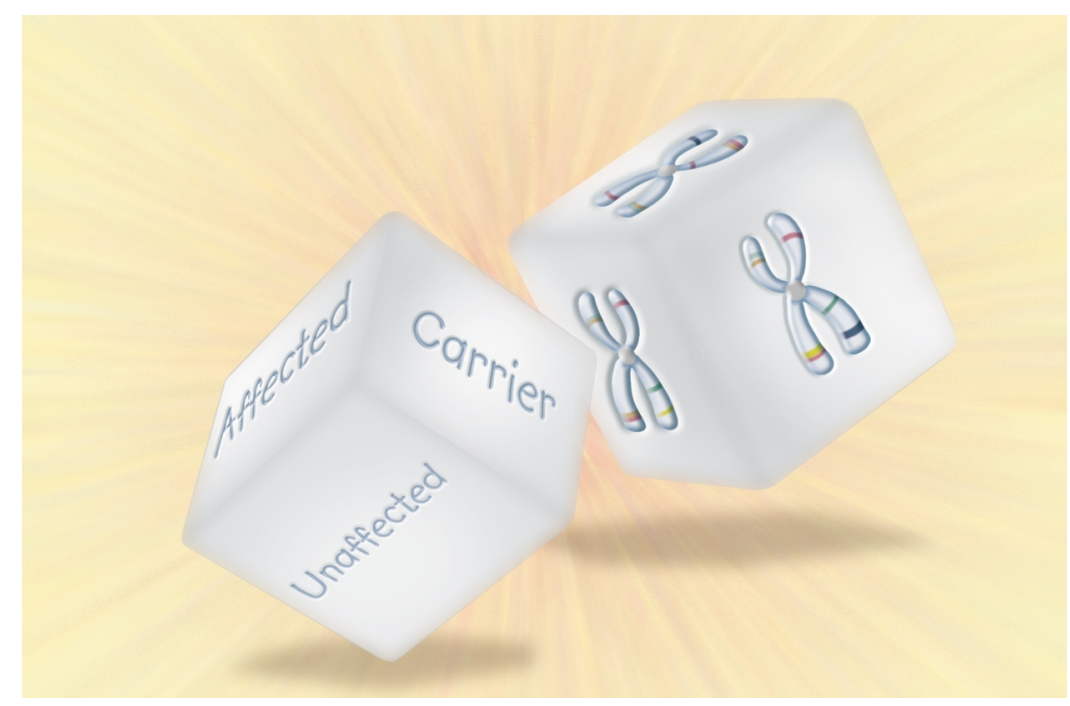

Figure 1

Genetic counseling for individuals at risk for common disorders is increasing.

Human Genetics in 1975 (3) is under transition as the field of genetic counseling has grown with the demands of genomic medicine (4-6). Traditionally, genetic counseling has centered on prenatal and pediatric genetic diagnoses and decision-making involving reproduction. However, counseling for individuals at risk for common disorders is increasing (Figure 1). Genetic counseling focuses on complex issues related to the value of genetic testing itself, and on medical interventions and health care practices that have varying degrees of efficacy and success (5). The traditional dogma that genetic counseling must be nondirective is being challenged in favor of a psychosocial approach that emphasizes shared deliberation and decision-making between the counselor and the client. The genetic counseling intervention is designed to reduce the client's anxiety, enhance the client's sense of control and mastery over life circumstances, increase the client's understanding of the genetic disease and options for testing and disease management, and provide the individual and family with the tools required to adjust to potential outcomes (7-10). The information provided during genetic counseling helps the individual and family personalize often threatening information in order to clarify their values and strengthen their coping mechanisms (11). A major tenet of all factors, and identifying medical screening needs for healthy individuals. A pedigree is an important method of establishing patient rapport. It also serves as a visual demonstration for providing patient education on variation in disease expression in the family as well as identifying other relatives at risk for disease (14).

Statistical risk assessment based on pedigree analysis and the results of any genetic testing in the patient or other relatives is central to genetic counseling. Counselors explore clients' preconceived notions about patterns of inheritance, chances of testing positive or developing the family disorder, and the burden (e.g., morbidity, mortality, financial and psychological difficulties) of the disease. If genetic counseling information diverges from a client's perceptions, the client may have difficulty incorporating it or implementing disease-management recommendations. Risk information must be provided in multiple forms. For example, the client may perceive a tenfold increase in the relative risk of developing disease as quite high, when the absolute risk may be only $2 \%$. Likewise, a 1 in 20 chance of developing a condition may be perceived as much more significant than a $95 \%$ chance that they will be free of the disease.

While pedigree analysis and risk assessment may seem the most difficult aspect of genetic counseling, in reality, addressing the myriad reactions and emotions of clients responding to a genetic diagnosis can be far more challenging (14-17) (see Psychological dilemmas, emotions, and reactions commonly encountered during genetic counseling). This may involve more than one appointment, or referral for psychotherapy. Because a genetic diagnosis may have serious ramifications for a client's extended family, it is paramount that the client be enabled to make an informed decision as to whether to be tested. There is a general trend for health professionals to refer clients to a genetic counselor only after the client has received a positive test result. In reality, the most appropriate stage at which to make a referral is early in the consideration of initial genetic testing or diagnosis. 


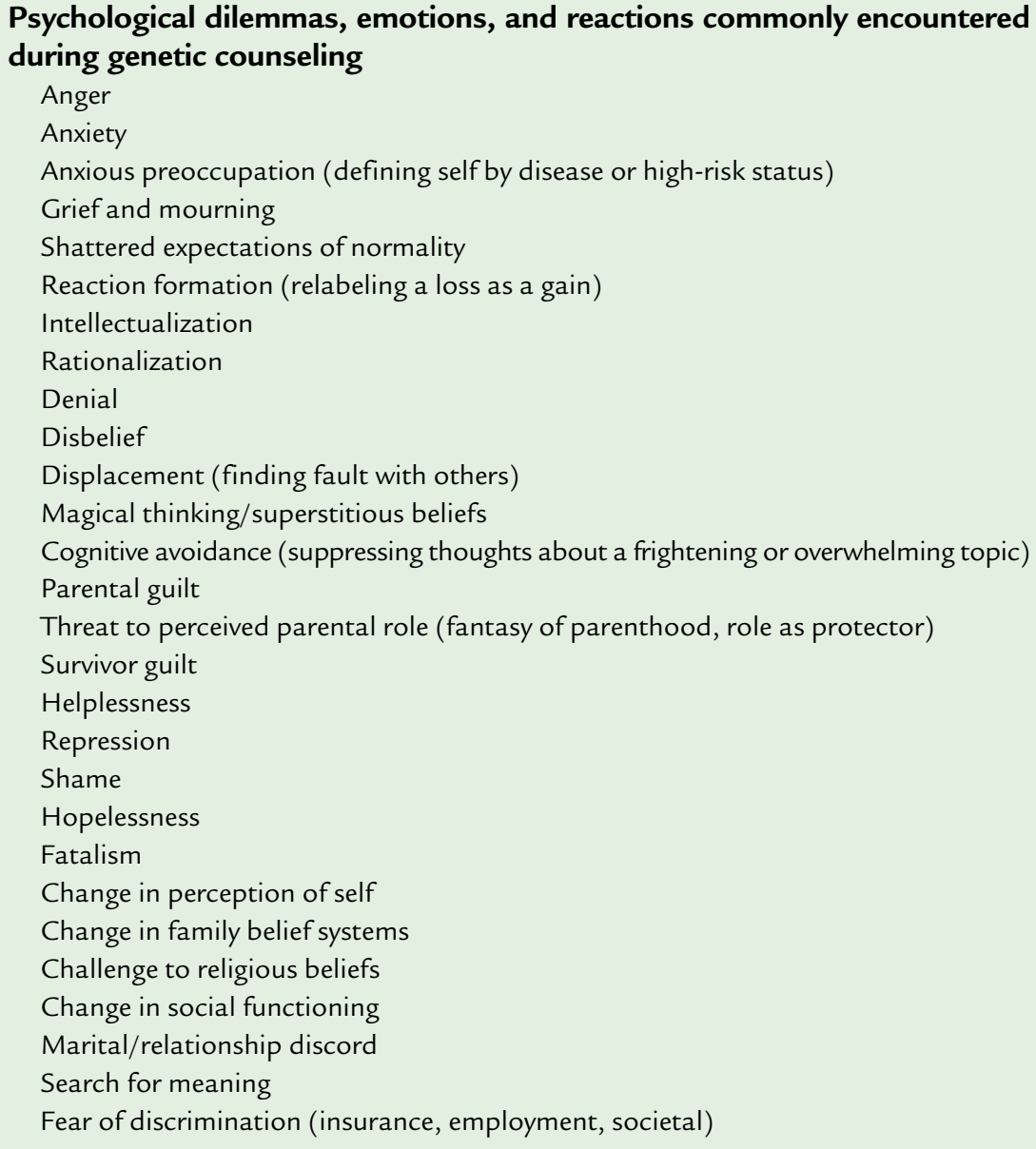

\section{Challenges to the paradigm of health and disease}

The era of genomic medicine challenges traditional definitions of "healthy" and "diseased." Traditionally, individuals have sought medical attention out of concern regarding a present illness. Genetic testing facilitates diagnosis of a healthy individual who is expected to develop or has an increased susceptibility to develop a disorder. A class of individuals is created who may be perceived as "genetically unwell" (18). The emotional consequences of diagnosing a healthy person as "diseased" can be profound. There are also instances of survivor guilt, where a healthy individual feels guilty upon testing negative for a family-related genetic condition because he or she has "escaped" the disease whereas other family members have not. Presymptomatic or susceptibility tests have been readily available only since the early 1990s, so the data on their impact are limited. The data suggest that most individuals cope well with the results of these tests, perhaps partly because the tests, to date, have been primarily requested by genetic counselors and medical geneticists specifically trained to help patients interpret the complex information, often with the luxury of 60to 90 -minute visits. With the push to provide genetic testing in primary care settings where appointments are often limited in time, as well as to market tests directly to consumers, it will be interesting to see whether genetic information continues to be well handled.

\section{Testing minors for adult-onset disorders}

Genetic testing of healthy children for predisposition for adult-onset disorders is a further area of controversy. Is it the parents' right to know whether a child will develop Huntington disease or familial ovarian cancer? Perhaps the parents wish to make informed choices regarding their child's academic track and insurance coverage and be aware of possible factors in their child's future reproductive choices. Statements from several professional societies suggest that genetic testing for disorders with no medical interventions is unwarranted in healthy children (19-21). This protection of the child's rights is based on the observation that many adults at risk for conditions such as cancer or Huntington disease choose not to be tested, which makes it unfair for parents or health professionals to take this decision from the child. This reasoning is extended to conclude that women have the right to choose prenatal diagnosis for adult-onset conditions only if they are considering terminating the pregnancy as a result of the diagnosis. That is, a woman should not have prenatal diagnosis "just to know," if she would not terminate the pregnancy, since then a child would be born who would not normally be tested for the condition. Some individuals who do not want to pass a genetic condition to a child, but also do not want to terminate a mutation-positive pregnancy, choose to have genetic diagnosis before implantation. By implanting only embryos that will not have the genetic disease in question, the couple avoids the possibility of having to terminate an affected fetus.

\section{Cancer: a new paradigm for genetic counseling}

Genetic counseling for cancer is one of the newest subspecialties in the field. It began at major cancer centers in the early 1990s, mainly through the identification of families suitable for genehunting studies, since few cancer susceptibility genes were known. As inherited syndromes involving common cancers such as breast and colon cancer were identified, the genetic counseling field grew rapidly. Counseling positions were created at most cancer hospitals and in large oncology groups - areas previously uninhabited by the profession. In 2002, the NSGC Professional Status Survey indicated that $42 \%$ of genetic counselors worked in the field of cancer 
Table 1

Differential diagnosis for familial breast cancer

\begin{tabular}{|c|c|c|c|}
\hline Syndrome & Gene(s) & Breast cancer risk & Other associated cancers \\
\hline Hereditary breast-ovarian cancer syndrome & $B R C A 1$ and $B R C A 2$ & $45-85 \%(14)$ & Ovarian, prostate \\
\hline Cowden syndrome & PTEN & $25-50 \%(47,48)$ & Thyroid, endometrial \\
\hline Li-Fraumeni syndrome & TP53 & $50 \%(49)$ & Sarcoma, adrenocortical, brain, leukemia \\
\hline Peutz-Jeghers syndrome & STK11 & $\begin{array}{l}\mathrm{RR}=20.3 \text { (breast and } \\
\text { gynecologic cancers) }(50,51)\end{array}$ & $\begin{array}{l}\text { Gastrointestinal, pancreatic, } \\
\text { ovarian, uterine }\end{array}$ \\
\hline Carriers of ataxia telangiectasia & ATM & $\mathrm{RR}=1.5-7.1(52,53)$ & \\
\hline $\begin{array}{l}\text { Familial breast cancer/Hereditary breast } \\
\text { and colorectal cancer syndrome }\end{array}$ & CHK2 1100delC & $\mathrm{RR}=2(54)$ & Colon (55) \\
\hline
\end{tabular}

genetics, a fourfold increase from just $10.4 \%$ of counselors in 1994. This expansion of the cancer genetic counseling field is likely due to strong public interest, as cancer is a common disease, and to medical advances leading to the early detection, risk reduction, or prevention of cancer in those at the highest hereditary risk. Cancer genetics will serve as a paradigm for other adult-onset conditions as more predisposition genes are identified.

\section{Counseling for cancer: hereditary breast-ovarian cancer syndrome}

Cancer genetic counseling differs significantly from the traditional prenatal and pediatric consultation process (22). At least a three-generation pedigree is required to identify a hereditary pattern of cancers in a family, typically obtained prior to the counseling appointment. Emphasis is also placed on collecting medical records to document all cancer diagnoses, as the accuracy of a risk assessment depends on knowledge of the anatomical location of the disease and the ages of diagnosis of family members (23-29).

During the initial consultation, cancer genetic counselors obtain information on lifestyle risk factors and cancer-screening practices. They provide tailored cancer-surveillance recommendations based on the patient's risk level. Recommendations are provided in a directive manner, a departure from traditional nondirective genetic counseling. Since genetic counseling is a consultation service and is not involved in long-term management, patients return to their referring physicians and other medical specialists after counseling for the coordination of cancer surveillance. It is common for patients to have multiple genetic counseling sessions as part of a cancer genetics consultation, since patients who elect to pursue testing often return for a blood-draw appointment and are required to return for a resultdisclosure session.

The leading source of referrals in most cancer genetics programs is the evaluation of patients with a personal or family history of breast cancer. The differential diagnosis for these families includes several known cancer syndromes (Table 1), with hereditary breast-ovarian cancer syndrome (HBOC) (30-32) having the highest incidence. Mutations in the BRCA1 and $B R C A 2$ genes are most commonly associated with individuals and/or families with HBOC. BRCA1 and $B R C A 2$ are tumor-suppressor genes that serve protective functions in breast and ovarian cells. The protective functions of the BRCA1 protein include regulation of estrogen-receptor activity related to the control of estrogen-induced proliferation of breast tissue; involvement in homologous recombination and repair of transcription-coupled oxidation-induced DNA damage; cell-cycle checkpoint control through interactions with $R B, E S F 1$, and TP53; and involvement in chromatin remodeling (31). BRCA2 functions in homologous recombination, interacts with TP53 in cell-cycle checkpoint control, and is involved in chromatin remodeling (31). Individuals inheriting a germline mutation in $B R C A 1$ or BRCA2 need only acquire a mutation in the working copy of their $B R C A$ gene in an at-risk cell during their lifetime to lose these protective functions and to eventually develop cancer, also known as the multi-hit model of tumorigenesis as first proposed by Knudson in 1971 (33).

$B R C A$ gene mutations are inherited in an autosomal dominant pattern, so that children of an affected individual have a $50 \%$ chance of inheriting HBOC. Individuals with a $B R C A 1$ gene mutation appear to have a $65-85 \%$ lifetime risk of breast cancer and a 39-60\% lifetime risk of ovarian cancer (34). Women with a mutation in their BRCA2 gene have a $45-85 \%$ lifetime risk of breast cancer and an 11-25\% lifetime risk of ovarian cancer (34). An increased risk for prostate cancer has been noted in men with mutations in either gene (35). Male breast cancer and pancreatic cancer have also been associated with $B R C A 2$ gene mutations (36, 37). Management for individuals with HBOC includes monthly breast selfexamination beginning at age 18 , clinical breast examination every 6 months beginning at age 25 , and annual mammography beginning at age $25(38,39)$. Ovarian cancer surveillance, the efficacy of which is unproven, consists of transvaginal ultrasound with colorDoppler and cancer antigen-125 (CA125) tumor marker tests every 6 months beginning between the ages of 25 and $35(38,39)$. Chemoprevention may also hold promise for reducing the risk of cancer among women with HBOC. Many individuals with $B R C A$ mutations elect to undergo riskreducing surgeries such as mastectomy or bilateral salpingo-oophorectomy. While these surgeries significantly reduce the risk of cancer, they do not eliminate it $(40,41)$.

Genetic testing for the BRCA1 and $B R C A 2$ genes has been clinically available in the US since late 1996 from a single laboratory. There are three pos- 
sible results to a full-sequence test for these genes: (a) a positive result means that a cancer-causing mutation was identified; (b) a negative result means that no mutations were identified; and (c) an ambiguous result means that a genetic variant of uncertain significance was identified. Variants of uncertain significance (usually missense mutations) create a counseling challenge, since they may or may not lead to an increased risk for cancer in the family. These mutations warrant further analysis within the family and in research laboratories before predictive testing can be offered to other atrisk family members. In addition, a negative sequence result does not completely rule out the presence of mutations in $B R C A 1$ or BRCA2, as sequencing cannot detect large gene rearrangements or rare regulatory mutations.

\section{Gene patents and the future of diagnostic testing}

The laboratory that performs $B R C A$ gene testing has held US patents on the BRCA test since 1999 and European patents on the BRCA1 test since 2001 (42). The issue of gene patents remains controversial given that not all testing techniques can detect all mutations and that the presence of a patent deters researchers from developing new and perhaps better testing methods and therapeutics. Furthermore, patients must use one laboratory, which has little incentive to offer competitive pricing. In late August 2002 , several scientists, genetic testing laboratories, and genetics societies in France, Belgium, The Netherlands, Sweden, the United Kingdom, Spain, and Germany joined together to file opposition with the European Patent Office $(42,43)$. In Canada, several provincial governments have told their health authorities to continue BRCA1 and BRCA2 testing while they fight the patent through legal channels (44). However, proponents of gene patents note that without the ability to recoup costs through patents, laboratories will have no incentive to invest in the research and development necessary to find new genes involved in disease. In 2002, the laboratory currently offering $B R C A 1$ and $B R C A 2$ testing made another con- troversial move by initiating a campaign of marketing directly to consumers, following in the footsteps of pharmaceutical companies. The Atlanta and Denver areas were targeted by print, radio, and television advertisements encouraging women to consider genetic testing for HBOC (45). Critics feel that this could lead to increased health care costs resulting from inappropriate testing, and to a false sense of reassurance in individuals found not to have a gene mutation who are not informed about the limitations of these tests $(45,46)$. The laboratory also provides training to health care providers whom it does not employ and who do not necessarily have a background in genetics or genetic counseling. Many consider this to entail a conflict of interest, since these providers are trained to give cancer genetic consultations that will likely lead to an increase in requests for this laboratory's tests. These issues, among others, underscore the importance of thorough cancer genetic counseling for all patients who are considering genetic testing so that they can understand what the test can and cannot tell them, determine whether they are appropriate candidates for testing, and give truly informed consent.

Cancer genetic counseling and predictive genetic testing are complex and time consuming, so most physicians prefer to refer patients to specialists in this area. Genetic counseling will likely become more widely used in many fields of medicine as genes for other common adult-onset conditions are discovered - for instance, genes related to cardiovascular disease or psychiatric conditions. The model of cancer genetics can be applied to these new subspecialties as an effective way to integrate counseling services with the services of other medical professionals and researchers.

1. Marks, J.H., and Richter, M.L. 1976. The genetic associate: a new health professional. Am. J. Public Health. 66:388-390.

2. Walker, A.P. 1998. The practice of genetic counseling. In A guide to genetic counseling. D.L. Baker, J.L. Schuette, and W.R. Uhlmann, editors. WileyLiss Inc. New York, New York, USA. 1-26.

3. Ad Hoc Committee on Genetic Counseling. 1975. Report to the American Society of Human Genetics. Am. J. Hum. Genet. 27:240-242.

4. Biesecker, B., and Peter, K. 2002. Genetic coun- seling: ready for a new definition? J. Genet. Couns. 11:536-537. (Abstr.)

5. Weil, J. 2003. Psychosocial genetic counseling in the post-nondirective era: a point of view. J. Genet. Couns. 12:199-211.

6. Biesecker, B.B. 2003. Back to the future of genetic counseling: commentary on "psychosocial genetic counseling in the post-nondirective era." J. Genet. Couns. 12:213-217.

7. Burke, W., Pinsky, L.E., and Press, N.A. 2001. Categorizing genetic tests to identify their ethical legal and social implications. Am. J. Med. Genet. 106:233-240.

8. Elwyn, G., Gray, J., and Clarke, A. 2000. Shared decision making and non-directiveness in genetic counseling. J. Med. Genet. 37:135-138.

9. Jansen, L.A. 2001. Role of the nurse in clinical genetics. In Genetics in the clinic: clinical, ethical and social implications for primary care. M.B. Mahowald, A.S. Scheurle, V.A. McKusick, and T.J. Aspinwall, editors. Mosby Publishing. St. Louis, Missouri, USA. 133-141.

10. McConkie-Rosell, A., and Sullivan, J.A. 1999 Genetic counseling: stress, coping, and the empowerment perspective. J. Genet. Couns. 8:345-357.

11. Shiloh, S., Berkenstadt, M., Meiran, N., Bat-Miriam-Katznelson, M., and Goldman, B. 1997. Mediating effects of perceived personal control in coping with a health threat: the case of genetic counseling. J. Appl. Soc. Psychol. 27:1146-1174.

12. Bennett, R.L., Steinhaus, K.A., Uhrich, S.B., and O'Sullivan, C. 1993. The need for developing standardized pedigree nomenclature. J. Genet. Couns. 2:261-273.

13. Bennett, R.L., et al. 1995. Recommendations for standardized human pedigree nomenclature. $\mathrm{Am}$. J. Hum. Genet. 56:745-752.

14. Bennett, R.L. 1999. The practical guide to the genetic family history. Wiley-Liss Inc. New York, New York, USA. 251 pp.

15. Schneider, K. 2002. Counseling about cancer: strategies for genetic counseling. Wiley-Liss Inc. New York, New York, USA. 333 pp.

16. 2000. Psyche and helix: psychological aspects of genetic counseling. R.G. Resta, editor. Wiley-Liss Inc. New York, New York, USA. 180 pp.

17. Weil, J. 2000. Psychosocial genetic counseling. Oxford University Press. New York, New York, USA. 291 pp.

18. Jonsen, A.R., Durfy, S.J., Burke, W., and Motulsky, A.G. 1996. The advent of the "unpatients." Nat. Med. 2:622-624

19. American Society of Human Genetics/American College of Medical Genetics Reports. 1995. Points to consider: ethical, legal and psychological implications of genetic testing in children and adolescents. Am. J. Hum. Genet. 57:1233-1241.

20. National Society of Genetic Counselors. 1994 Position statement on prenatal and childhood testing for adult-onset disorders. Perspectives in Genetic Counseling. 17:5.

21. American Academy of Pediatrics, Committee on Genetics. 2000. Molecular genetic strategies in pediatric practice: a subject review. Pediatrics. 106:1494-1497.

22. Peters, J.A., and Biesecker, B.B. 1997. Genetic counseling and hereditary cancer. Cancer Supplement. 80:576-586.

23. Douglas, F., O’Dair, L., Robinson, M., Evans, D.G., and Lynch, S.A. 1999. The accuracy of diagnoses as reported in families with cancer: a retrospective study. J. Med. Genet. 36:309-312.

24. Schmidt, S., Becher, H., and Chang-Claude, J. 1998. Breast cancer risk assessment: use of complete pedigree information and the effect of misspecified ages at diagnosis of affected relatives. Hum. Genet. 102:348-356.

25. Bergmann, M., et al. 1998. Validity of self-reported cancers in a prospective cohort study in comparison with data from state cancer registries. Am. J. Epidemiol. 147:556-562. 
26. Parent, M., Ghadirian, P., Lacroix, A., and Perret, C. 1997. The reliability of recollections of family history: implications for the medical provider. J. Cancer Educ. 12:114-120.

27. Aitken, J., Bain, C., Ward, M., Siskind, V., and MacLennan, R. 1995. How accurate is self-reported family history of colorectal cancer? Am. J. Epidemiol. 141:863-871.

28. Love, R., Evans, A., and Josten, D. 1985. The accuracy of patient reports of a family history of cancer. J. Chronic Dis. 38:289-293.

29. Novakovic, B., Goldstein, A.M., and Tucker, M.A. 1996. Validation of family history of cancer in deceased family members. J. Natl. Cancer Inst. 88:1492-1493.

30. Lynch, H.T., Snyder, C.L., Lynch, J.F., Riley, B.D., and Rubinstein, W.S. 2003. Hereditary breastovarian cancer at the bedside: role of the medical oncologist. J. Clin. Oncol. 21:740-753.

31. Narod, S.A. 2002. Modifiers of risk of hereditary breast and ovarian cancer. Nat. Rev. Cancer. 2:113-123.

32. Robson, M.E. 2002. Clinical considerations in the management of individuals at risk for hereditary breast and ovarian cancer. Cancer Control. 9:457-465.

33. Knudson, A.G. 1971. Mutation and cancer: statistical study of retinoblastoma. Proc. Natl. Acad. Sci. U. S. A. 68:820-823.

34. Antoniou, A., et al. 2003. Average risks of breast and ovarian cancer associated with BRCA1 or BRCA2 mutations detected in case series unselected for family history: a combined analysis of 22 studies. Am. J. Hum. Genet. 72:1117-1130.

35. Struewing, J.P., et al. 1997. The risk of cancer asso- ciated with specific mutations of BRCA1 and BRCA2 among Ashkenazi Jews. N. Engl. J. Med. 336:1401-1408.

36. Wooster, R., et al. 1994. Localization of a breast cancer susceptibility gene, BRCA2, to chromosome 13q12-13. Science. 265:2088-2090.

37. 1999. Cancer risks in BRCA2 mutation carriers. The Breast Cancer Linkage Consortium. J. Natl. Cancer Inst. 91:1310-1316.

38. Burke, W., et al. 1997. Recommendations for follow-up care of individuals with an inherited predisposition to cancer. II. BRCA1 and BRCA2. Cancer Genetics Studies Consortium. JAMA 277:997-1003.

39. Daly, M. 2002. National Comprehensive Cancer Network Practice Guidelines. Genetic/Familia high-risk assessment: breast and ovarian. Version 1.2003. http://www.nccn.org/physician_gls/f_guidelines.html.

40. Rebbeck, T.R., et al. 2002. Prophylactic oophorectomy in carriers of BRCA 1 or BRCA 2 mutations. N. Engl.J. Med. 346:1616-1622.

41. Hartmann, L., et al. 2001. Efficacy of bilateral prophylactic mastectomy in BRCA1 and BRCA2 gene mutation carriers. J. Natl. Cancer Inst. 93:1633-1637.

42. Benowitz, S. 2003. European groups oppose Myriad's latest patent on BRCA1. J. Natl. Cancer Inst. 95:8-9.

43. Matthijs, G., et al. 2002. Patents and monopolies on diagnostic tests: Europe's opposition against the BRCA1 patents. Am. J. Hum. Genet. 71:182. (Abstr. 93).

44. 2003. Gene patents and the public good. Nature 423:207.

45. Pearson, H. 2003. Genetic test adverts under scrutiny. Nature Science Update. http:// www.nature.com/nsu/030317/030317-3.html.

46. Moreno, J. 2002. Selling genetic tests: shades of gray in your DNA. ABCNEWS.com. http://abcnews.go.com/sections/living/DailyNews/ONCAL L_DTC_brca_tests020923.html.

47. Starink, T.M., et al. 1986. The Cowden syndrome: a clinical and genetic study in 21 patients. Clin Genet. 29:222-233.

48. Brownstein, M.H., Wolf, M., and Bilowski, J.B. 1978. Cowden's disease: a cutaneous marker of breast cancer. Cancer. 41:2393-2398.

49. Li, F.P., et al. 1988. A cancer family syndrome in twenty-four kindreds. Cancer Res. 51:6094-6097.

50. Boardman, L., et al. 1998. Increased risk for cancer in patients with the Peutz-Jeghers syndrome. Ann. Intern. Med. 128:896-899.

51. Giardiello, F.M., et al. 1987. Increased risk of cancer in the Peutz-Jeghers syndrome. N. Engl. J. Med. 316:1511-1514.

52. Olsen, J.H., et al. 2001. Cancer in patients with ataxia-telangiectasia and in their relatives in the Nordic countries. J. Natl. Cancer Inst. 93:84-85.

53. Swift, M., Morrell, D., Massey, R.B., and Chase, C.L. 1991. Incidence of cancer in 161 families affected by ataxia-telangiectasia. $N$. Engl. J. Med. 325:1831-1836.

54. Meijers-Heijboer, H., et al. 2002. Low-penetrance susceptibility to breast cancer due to CHEK2(*)1100delC in noncarriers of BRCA1 or BRCA2 mutations. Nat. Genet. 31:55-59.

55. Meijers-Heijboer, H., et al. 2003. The CHEK2 1100 delC mutation identifies families with a hereditary breast and colorectal cancer phenotype. Am. J. Hum. Genet. 72:1308-1314. 